\title{
Spatial variation in reproductive measures of female bluegill Lepomis macrochirus Rafinesque in a small lake with diverse thermal conditions
}

\author{
Yoshimasa Yamamoto ${ }^{*}$ and Fuh-Kwo Shiah
}

\begin{abstract}
Background: Our previous studies have revealed that bluegill Lepomis macrochirus Rafinesque in Lake Biwa exhibit spatial variations in growth, maturation, and reproduction. The topographical characteristics of Lake Biwa produce a wide range of thermal conditions, which seem to be responsible for those findings. Despite its small size, Lake Yogo is characterized by diverse thermal conditions owing to the presence of a small, shallow pool in the northern part of the lake and the inflow of water from Lake Biwa into the southern part of the lake. Whether bluegill in such a small lake also exhibit spatially varying physiological activity remains uncertain.

Results: The maturation status of female bluegill in Lake Yogo was investigated from late April to early June 2011 and in late May 2012. The gonadosomatic index (GSI) of the fish in the pool significantly exceeded those in the main lake in late April and mid-May 2011 before the onset of spawning. The spawning of bluegill had probably already begun by late May 2012, and the fish in the pool and along the northwestern edge of the lake had smaller GSIs than did the fish in the southern part of the lake. The relationship between oocyte diameter and GSI could be described by a saturation function. The plot of GSI/Oocyte diameter vs. GSI did not vary significantly among the sites.

Conclusions: The maturation status of bluegill varied among sites in Lake Yogo, likely to be due to the diverse thermal conditions of the lake. Higher temperatures in the pool during the prespawning season favored the rapid maturation of ovaries of the fish therein. The inflowing colder water from Lake Biwa seemed to be responsible for delayed ovary maturation and, thereby, the delay in the spawning season of bluegill in the southern part of the lake.
\end{abstract}

Keywords: Bluegill; Lake Yogo; Gonadosomatic index; Oocyte; Thermal condition

\section{Background}

The bluegill Lepomis macrochirus Rafinesque is a common freshwater fish in Japan, inhabiting lentic water bodies such as lakes, ponds, and the lower reaches of rivers (Nakai 2002). They gradually spread following their introduction from the USA in 1960, until they were present throughout the country as of 2006 (Yonekura et al. 2007). The high adaptability of bluegill may be associated with their life-history strategies (Gross and MacMillan 1981; Gross 1982; Nakao et al. 2006), and also their physiological flexibility. Our previous studies in Lake Biwa, the largest lake in Japan with a surface area of $670 \mathrm{~km}^{2}$, have revealed that patterns of growth, maturation, and reproduction of

\footnotetext{
* Correspondence: yyama@rcec.sinica.edu.tw

* Correspondence: yyama@rcec.sinica.edu.tw
Research Center for Environmental Changes, Academia Sinica, 128 Academia Rd., Sec. 2, Taipei 11529, Taiwan
}

bluegill tend to vary with latitude (Yamamoto et al. 2010, 2011; Yamamoto and Kao 2012; Yamamoto and Shiah 2012). Lake Biwa consists of a deep northern main basin and a shallow southern sub-basin. These topographical characteristics cause the lake water to warm up and cool down from the south, such that the thermal environment of the lake somewhat depends on latitude despite its small size on a global scale (Yamamoto and Kao 2012). Given the critical importance of temperature in regulating the growth and reproduction of bluegill (Nakamura et al. 1969; Lemke 1977), temperature appears to be responsible for those findings.

Lake Yogo is a small lake (surface area $=1.7 \mathrm{~km}^{2}$, maximum depth $=13.3 \mathrm{~m}$ ) located $1.3 \mathrm{~km}$ north of Lake Biwa. Although originally a closed system, this lake has been serving as a water storage dam for over 3 decades, the water level of which is controlled by the inflow from the

\section{国 Springer}


Yogo River, pumping up from Lake Biwa and discharge to the Yogo River (Tsujimura 2004, see Figure 1). Since the inflowing water from Lake Biwa is colder than the Lake Yogo water in early summer (Tsukada et al. 2006), the inflowing water appears to contribute to cooling Lake Yogo, at least in its narrow southern area. In addition, an underwater dike at the northern edge of the lake was constructed in 1978 to prevent a buried forest (Horie et al. 1975) from drying out when the water level of the lake drops due to discharge of the lake water. The small area of water on the north side of the dike (surface area $=0.002$ $\mathrm{km}^{2}$; hereafter referred to as the 'pool') has a maximum depth of less than $1 \mathrm{~m}$ and so is assumed to warm up more rapidly than the main lake from spring to summer. The presence of bluegill in Lake Yogo has been known since the late 1980s (Lake Yogo Fishery Cooperative Association, personal communication), whereas exactly when the bluegill began to inhabit the lake is uncertain, because they were not officially introduced into the lake. The population of bluegill in Lake Yogo appears to have dramatically increased in recent years as large schools of bluegill, which were never observed in the early 2000s $(\mathrm{H}$. Tsukada, personal communication), can now be observed in the littoral zone throughout the lake.

In a large water body, bluegill may exhibit spatial variation in physiological activity as a consequence of adaptation to local environments. In Lake Biwa, the variation in thermal conditions is assumed to be largely responsible for the spatial variations in the maturation and growth of bluegill; however, not only temperature but also other biotic and abiotic factors may also greatly vary within the lake, making it difficult to definitively attribute spatial variation in the physiological activity of bluegill to local thermal conditions. In contrast, if a bluegill population in a small water body with diverse thermal environments is demonstrated to exhibit a predictable spatial variation in physiological activity, then such a finding would be strong evidence of the temperature-dependent adaptive response of bluegill.

The propagation of bluegill in Lake Yogo provides a valuable opportunity to investigate whether diverse thermal environments in a small lake can cause the bluegill to exhibit spatial variation in the physiological activity. The temperature in the littoral zone of Lake Yogo from spring to summer would be highest in the shallow pool and lowest at the southern edge where colder water flows in from Lake Biwa. Therefore, if the maturation of bluegill is strongly affected by temperature, then the fish in the pool are expected to have gonads that are more mature than those in the main lake during the prespawning season. Fish that mature earlier would spawn earlier, so the gonads of early spawning fish would be smaller than those of fish

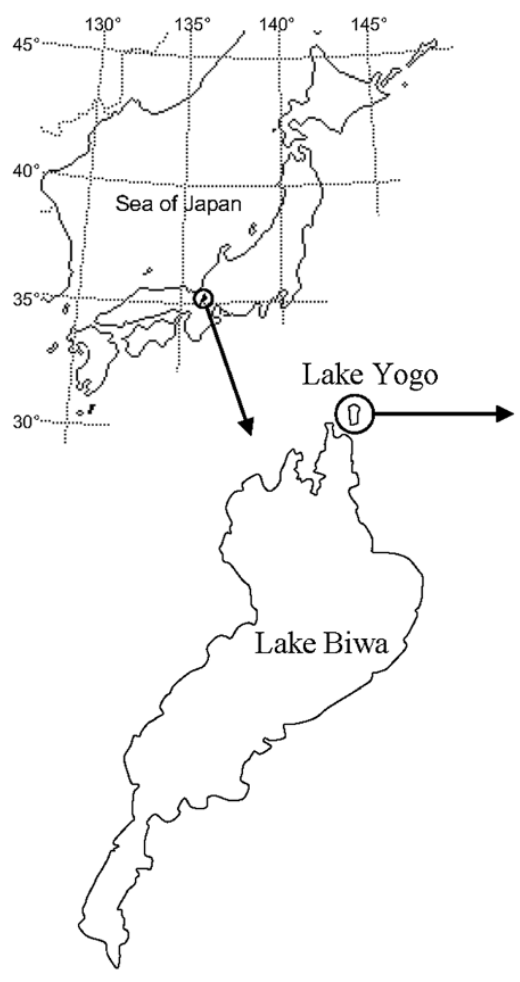

Figure 1 Map of Lake Yogo showing the sampling sites.

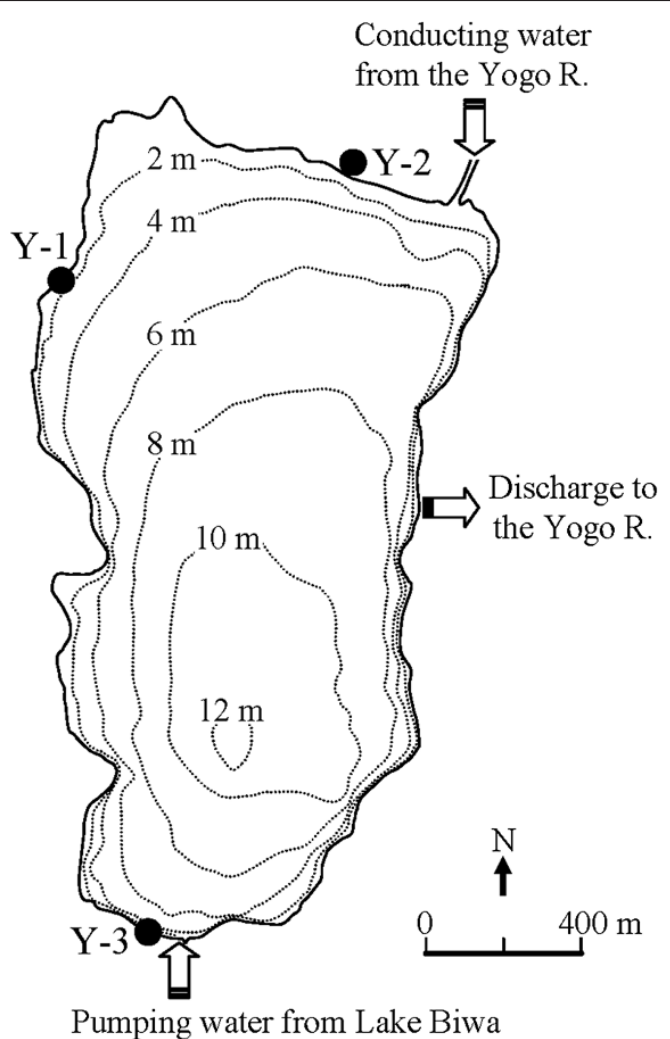

Pumping water from Lake Biwa 
that spawn later during the spawning season. Consequently, the fish at the southern edge of the lake are expected to have larger gonads than those at other sites following the onset of spawning. To examine this hypothesis, reproductive measures of bluegill females, such as the gonadosomatic index (GSI) and oocyte size, were compared among three sites in the lake.

\section{Methods}

The bluegill were collected by hook and line at three sites in Lake Yogo: site Y-1 on the northwest edge of the lake, site Y-2 in the pool, and site Y-3 on the southern edge of the lake within $100 \mathrm{~m}$ of the gate through which water flows in from Lake Biwa (Figure 1). The bluegill usually begin to spawn when the ambient temperature reaches approximately $20^{\circ} \mathrm{C}$, and they continue spawning for 2 to 3 months (Nakamura et al. 1969; Nakao et al. 2006). The temperature of the surface layer of Lake Yogo usually reaches $20^{\circ} \mathrm{C}$ in May (Tsujimura 2004; Tsukada et al. 2006). Therefore, to collect fish samples during the prespawning season or early in the spawning season, sampling was conducted on 30 April, 13 May, and 1 June in 2011 and on 31 May in 2012. No samples were collected at site Y-3 in 2011 because of a lack of continuous pumping of water from Lake Biwa in April and May. The surface water temperature at each site was measured using a stick thermometer at around noon. Captured fish were immediately euthanized with an overdose of ethyl 3-aminobenzoate methanesulfonate salt (MS-222). Collection of fish and experimentation adopted in the study comply with the requirements of the guidelines for the use of fishes in research decided by the Ichthyological Society of Japan.

The standard lengths (SL) of specimens were measured to the nearest $0.01 \mathrm{~mm}$ with a CD-8 "CSX digital caliper (Mitsutoyo, Kanagawa, Japan) and body weights were measured to the nearest $0.1 \mathrm{~g}$ with an MP-1000 portable digital scale (Ashiba, Taipei, Taiwan). Bluegill males have alternative reproductive pathways termed "parental" and "cuckolder" that are associated with different testis sizes (Gross 1982), and social interactions strongly affect the maturation of parental males (Jennings et al. 1997; Aday et al. 2003), complicating the analysis of the relationship between temperature and testis maturation. In contrast, females lack alternative reproductive pathways, so maturation of their ovaries is more directly controlled by temperature. Therefore, in this study, only females were used in the analyses. Ovaries were isolated and weighed to the nearest $0.002 \mathrm{~g}$ using a $1210 \mathrm{~N}$ portable digital scale (Tanita, Tokyo, Japan). The maturation status of each specimen was evaluated based on the GSI, which was calculated as ovary weight/body weight $\times 100$.

Oocyte maturation was examined using specimens collected in 2012. Oocytes were sampled from the midsection of ovaries using a plastic spoon and then preserved in vials filled with $5 \%$ Lugol's solution. Oocytes were observed under an inverted microscope (Axio Observer A1, Carl Zeiss, Göttingen, Germany) at $\times 50$ magnification. Images of at least 10 oocytes of the largest class were captured using a digital CCD camera (AxioCam MRm, Carl Zeiss), and their diameters were measured using the AxioVision 4.7 software (Carl Zeiss). Diameters of elliptical oocytes were expressed as the geometric means of the lengths of the major and minor axes. Diameters of the three largest oocytes were averaged to represent the oocyte diameter of each specimen. An oocyte with a diameter of $\geq 0.85 \mathrm{~mm}$ was considered to be mature (Banner and Hyatt 1975).

The GSI was expressed as a function of SL. Variation in GSI among sites was assessed by performing the analysis of covariance (ANCOVA) on the SL. However, the analysis of variance (ANOVA) or a two-tailed $t$ test was performed to assess the variation in the GSI among sites when at least one group failed to exhibit a significant correlation between the GSI and SL. To evaluate the relationship between the GSI and oocyte size, a plot of GSI vs. GSI/oocyte diameter was undertaken, and the difference in this relationship was assessed by ANCOVA. The level of statistical significance was set at $p<0.05$.

\section{Results and discussion \\ Results}

In 2011, no water was pumped from Lake Biwa until 1 July, except on 2 May (data not shown). Pumping in 2012 began on 10 May. Then, following a lack of pumping on 16 to 19 May, continuous pumping was resumed from 20 May $\left(0.38\right.$ to $2.20 \times 10^{5} \mathrm{~m}^{3} /$ day $)$. Difference in the surface water temperatures was small among the sites (Table 1). The temperature at site Y-2 exceeded that at site Y-1 except on 1 June 2011. The temperature at site Y-3 was the lowest among the three sites in 2012.

A total of 214 female specimens were collected in this study. Their SLs and GSIs are shown in Table 1. On average, the specimens collected in 2011 were larger than those in 2012. The GSI increased from late April to early June 2011. The mean GSI of the fish collected in late May 2012 was highest at site Y-3.

Figure 2 shows the relationship between the GSI and SL of bluegill. The GSI of the female bluegill collected in 2011 correlated closely with the SL, except for the specimens at site $\mathrm{Y}-1$ in late April (late April, site Y-1, $r=0.17$, $p=0.41$, site $\mathrm{Y}-2, r=0.45, p<0.05$; mid-May, site $\mathrm{Y}-1, r=$ $0.46, p<0.01$, site Y-2, $r=0.72, p<0.001$; early June, site $\mathrm{Y}-1, r=0.67, p<0.01$, site Y-2, $r=0.65, p<0.001)$. The GSIs of the fish at site Y-2 significantly exceeded those of the fish at site Y-1 in late April (two-tailed $t$ test, $t=2.81$, $d f=45, p<0.01$ ) and mid-May (ANCOVA, slope: $F_{1,64}=$ 4.72, $p<0.05$; intercept: $\left.F_{1,65}=4.63, p<0.05\right)$, whereas the GSIs did not significantly differ between these sites in early June (ANCOVA, slope: $F_{1,43}=0.90, p=0.35$; 
Table 1 Water temperature, standard length (SL), and gonadosomatic index (GSI) of female specimens (data are presented as mean $\pm \mathrm{SE}$ )

\begin{tabular}{lccccc}
\hline Date & Site & Temperature $\left({ }^{\circ} \mathbf{C}\right)$ & $\boldsymbol{n}$ & $\mathbf{S L}(\mathbf{m m})$ & GSI \\
\hline 30 April 2011 & Y-1 & 12.7 & 25 & $108.69 \pm 2.00$ & $1.83 \pm 0.08$ \\
& Y-2 & 13.0 & 22 & $117.43 \pm 2.23$ & $2.26 \pm 0.14$ \\
13 May 2011 & Y-1 & 18.0 & 38 & $107.22 \pm 2.06$ & $2.90 \pm 0.18$ \\
& Y-2 & 18.8 & 30 & $108.33 \pm 2.92$ & $3.54 \pm 0.33$ \\
1 June 2011 & Y-1 & 18.2 & 20 & $110.36 \pm 4.11$ & $6.93 \pm 0.86$ \\
& Y-2 & 18.0 & 27 & $109.03 \pm 2.56$ & $5.74 \pm 0.77$ \\
31 May 2012 & Y-1 & 22.5 & 16 & $93.41 \pm 4.75$ & $4.54 \pm 0.60$ \\
& $Y-2$ & 23.8 & 17 & $99.43 \pm 5.26$ & $4.07 \pm 0.58$ \\
& $Y-3$ & 21.0 & 19 & $107.49 \pm 6.39$ & $7.46 \pm 0.87$ \\
\hline
\end{tabular}

intercept: $F_{1,44}=1.49, p=0.23$ ). In 2012, only the fish collected at site Y-3 exhibited GSIs in excess of 10. Although specimens with an SL of greater than $100 \mathrm{~mm}$ at site Y-3 tended to have greater GSIs than specimens at sites Y-1 and Y-2, the ranges of GSIs of the smaller specimens at each site greatly overlapped. No significant correlation between the GSI and SL was detected (site Y-1, $r=0.017, p=$ 0.95 ; site Y-2, $r=-0.010, p=0.97$; site Y-3, $r=0.40, p=$ 0.09 ). The GSIs significantly varied among the sites (ANOVA, $F_{2,49}=6.80, p<0.01$ ).

Larger fish had insignificantly larger oocytes (site Y-1, $r=$ $0.20, p=0.45$; site $\mathrm{Y}-2, r=0.38, p=0.13$; site $\mathrm{Y}-3, r=0.38$, $p=0.10$ ) (Figure 3A). The relationship between oocyte diameter and the GSI could be described by a saturation function, as a plot of the GSI/oocyte diameter against the GSI yielded significant linear correlations (site Y-1, $r=$ $0.98, p<0.001$; site $\mathrm{Y}-2, r=0.97, p<0.001$; site $\mathrm{Y}-3, r=$ $0.96, p<0.001$ ) (Figure 3B,C). No significant difference in this plot was detected among the sites (slope: $F_{2,46}=1.12$, $p=0.33$; intercept: $\left.F_{2,48}=0.83, p=0.44\right)$. Percentages of females with mature oocytes were $18.8 \%$ at site Y-1, $11.8 \%$ at site $\mathrm{Y}-2$, and $57.9 \%$ at site $\mathrm{Y}-3$.

\section{Discussion}

This study demonstrates that the GSIs of bluegill vary among sites in Lake Yogo. Available data on water temperatures in Lake Yogo are limited, but we found the temperature in the littoral zone of the lake from prespawning through the spawning season of the bluegill to be highest in the shallow pool (site Y-2) and lowest at the southernmost point where colder water flows in from Lake Biwa (site Y-3), as confirmed by the measurements recorded on the sampling days. Yamamoto and Shiah (2013) showed that the bluegill in lagoons of Lake Biwa had larger ovaries than those in the main lake during the prespawning season, and they assumed that shallow lagoons warm up faster than the main lake, promoting ovary maturation. Likewise, the pool of Lake
Yogo warms up faster than the main lake, potentially favoring rapid ovary maturation of the bluegill. The greater GSIs of bluegill at site Y-2 than those at site Y-1 in late April and mid-May 2011 could therefore likely be attributed to the higher temperature of the pool. In contrast, the fish at site Y-3 exhibited greater GSIs than those at sites Y-1 and Y-2 in late May 2012. This result may have arisen from the fact that fish samples were collected during the spawning season, but the spawning of bluegill at site $\mathrm{Y}-3$ was not as advanced as that at sites Y-1 and Y-2. Overall, the results of this study were consistent with our prediction, supporting the critical importance of local thermal conditions in causing spatial variation in the maturation of bluegill in Lake Yogo. Given the small variation in temperature among sites, the maturation of the bluegill appears to be quite sensitive to ambient thermal conditions.

The GSI of fish normally increases during the prespawning season and peaks just prior to spawning (Mann 1980; Fox and Crivelli 1998). In 2011, the GSI of bluegill increased from late April until early June, suggesting that the bluegill likely had not yet spawned in late April and midMay, despite the fact that the water temperatures measured in mid-May were close to the threshold $\left(\mathrm{ca} .20^{\circ} \mathrm{C}\right)$ for the spawning of bluegill (Nakamura et al. 1969; Nakao et al. 2006). Some fish in early June 2011 exhibited high GSIs that were comparable to the highest GSIs of bluegill in the northern basin of Lake Biwa (Yamamoto and Shiah 2012); such fish might have been ready to spawn. In contrast, whether relatively large fish with low GSIs were in the midst of ovary maturation or had already begun spawning remains uncertain.

Water temperatures measured in late May 2012 exceeded the threshold for bluegill spawning; hence, the bluegill in the lake appeared to have already begun spawning when the sampling was carried out. Indeed, the fact that the GSIs of fish at sites Y-1 and Y-2 in late May 2012 were considerably lower than those in early June 2011 demonstrates that the spawning of bluegill had already begun when fish samples were collected. The greater GSIs of the fish at site Y-3 than those at sites Y-1 and Y-2 suggest that the bluegill at site Y-3 were reproductively more active than those at sites Y-1 and Y-2. The assumption that the spawning of bluegill at site Y-3 was not as advanced as that at sites Y-1 and Y-2 due to lower temperature explains why many fish at site Y-3 exhibited high GSIs and had mature oocytes.

Relatively small fish, of which only a few were captured in 2011, made up a significant portion of the specimens in 2012, and some of them exhibited high GSIs including those with mature oocytes. This result also suggests that the survey in 2012 was conducted during the spawning season of the bluegill. Larger individuals of many fish species are known to spawn before smaller ones (Miranda 


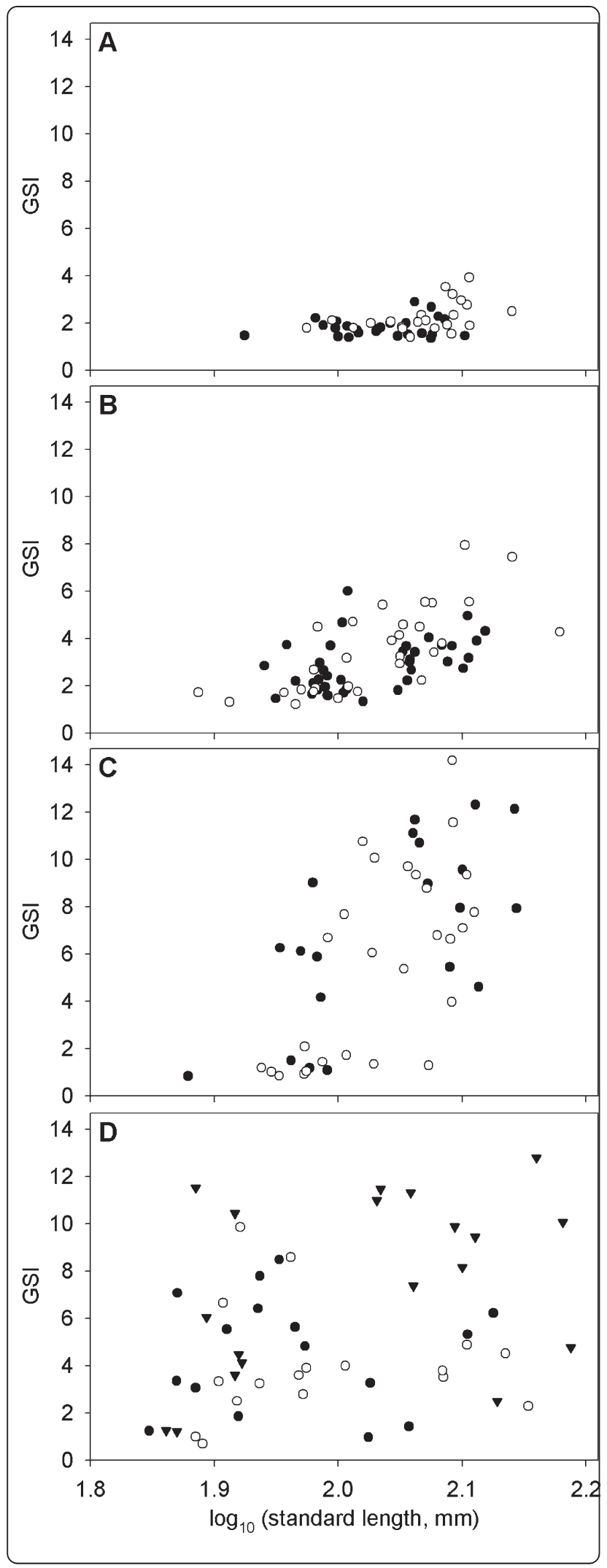

Figure 2 Relationship between gonadosomatic index (GSI) and standard length of bluegill. Fish samples were collected on 30 April 2011 (A), 13 May 2011 (B), 1 June 2011 (C), and 31 May 2012 (D) at sites Y-1 (closed circles), Y-2 (open circles), and Y-3 (closed triangles). No sample was collected from site $Y-3$ in 2011.

and Muncy 1987; Iguchi and Yamaguchi 1994; Knapp and Vredenburg 1996; Slotte et al. 2000; Vandeperre and Methven 2007). A similar size-dependent spawning time is true for bluegill (Cargnelli and Neff 2006); thus, the majority of large mature fish appeared to have had finished spawning at sites $\mathrm{Y}-1$ and $\mathrm{Y}-2$ and moved to the deeper offshore zone (Gross and MacMillan 1981), whereas spawning at site Y-3 was likely to have been in the early stage, and hence, large fish still remained close to the breeding colonies, explaining the absence of large females with mature oocytes at sites Y-1 and Y-2 and the presence of many large mature females at site Y-3 in late May 2012.

The GSI and largest oocyte size have been used as simple indicators of the maturation of fish (West 1990). The absence of a significant spatial difference in the GSIoocyte size relationship implies that the bluegill in Lake Yogo exert a definite reproductive effort regardless of site. Therefore, the spatial variation in the length-GSI relationship appears to be accounted for by the difference in the maturation status, rather than by the difference in the investment in reproduction. If the investment in reproduction of bluegill is consistent within Lake Yogo, then the ovary sizes of fish would eventually be almost the same at all sites, as partially verified by the absence of a significant difference between the GSIs of bluegill in the pool and main lake in early June 2011. Moreover, the highest class GSIs of bluegill at site Y-3 in late May 2012 were comparable to those exhibited by the fish at sites Y-1 and Y-2 in early June 2011 . This finding suggests the possibility that fish at all sites exhibited a similar length-GSI relationship just prior to the onset of spawning.

The spatial variation of reproductive measures of bluegill in Lake Yogo may imply that bluegill utilize a relatively narrow habitat during the reproductive season, and are consequently impacted by thermal conditions of each habitat. In fact, bluegill is often considered to be a sedentary species (Fish and Savitz 1983; Bayne et al. 2002), so assuming that they adapt to each habitat by optimizing physiological activity reasonably explains the findings of this study. However, the motility of bluegill may greatly vary among water bodies. A study conducted in Pelican Lake (332 ha) in Nebraska, USA, showed that the estimated home ranges of bluegill varied 0.13 to 172 ha (Paukert et al. 2004), suggesting that bluegill are potentially more mobile than they had been considered.

Bluegill are fractional and protracted spawners, and mature individuals participate in multiple spawning bouts over the course of a spawning season (Nakamura et al. 

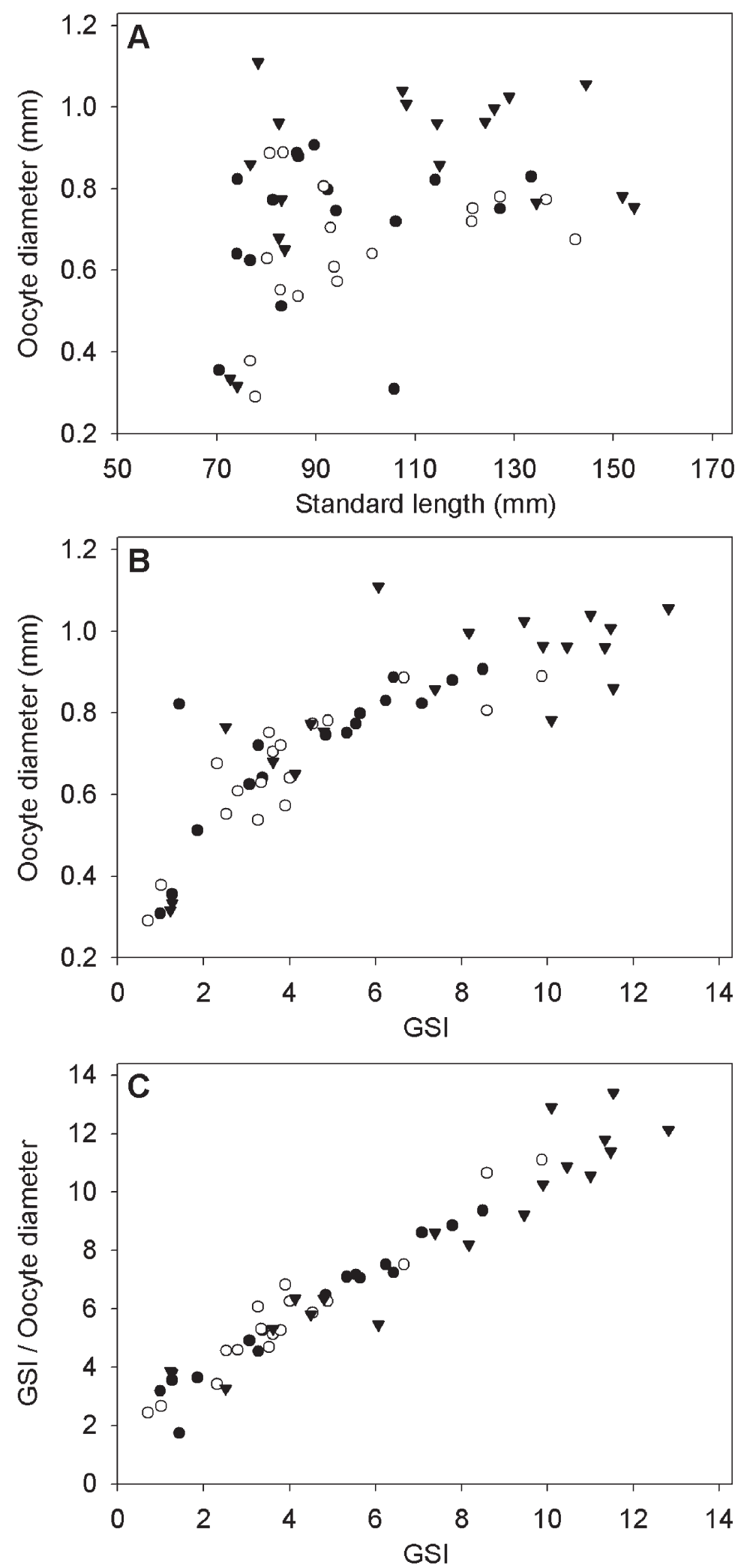

Figure 3 Reproductive measures of bluegill collected on 31 May 2012. Relationships between oocyte diameter and standard length (A), between oocyte diameter and gonadosomatic index (GSI) (B), and between the GSI/oocyte diameter and GSI (C) at sites Y-1 (closed circles), Y-2 (open circles), and Y-3 (closed triangles). 
1969; Gross 1982). The northern part of Lake Yogo has a more extensive littoral zone than the southern part, and thus is likely to have better spawning habitats for bluegill, which normally construct nests in shallow areas (Gross 1982; Nakao et al. 2006). In addition, the pelagic zone serves as an important foraging habitat for bluegill (Mittelbach 1981; Werner and Hall 1988), and such habitats appear to be more common in the southern part of the lake. Therefore, if Lake Yogo is sufficiently small for bluegill to travel across it, it may be possible that they mainly spawn in the northern part of the lake, then move toward the south to feed and improve their conditions prior to returning to the north to spawn (see Gross and MacMillan 1981). The possibility that the spatial variation in reproductive measures of bluegill in Lake Yogo is due to the separation of habitats for spawning and foraging cannot be ruled out. The spawning season and the migratory behavior of bluegill in Lake Yogo warrant further investigation.

\section{Conclusions}

Bluegill in Lake Yogo exhibited spatially varying maturation status. Higher temperatures in the pool favored the rapid ovary maturation of the fish therein. In contrast, the inflowing colder water from Lake Biwa seemed to be responsible for the delay in the ovary maturation of the fish in the southern part of the lake. However, the possibility that bluegill travel across the lake and utilize the northern shallow part for spawning and the southern deep part for foraging cannot be ruled out.

\section{Competing interests}

The authors declare that they have no competing interests.

\section{Authors' contributions}

YY designed the study, carried out fish sampling, and analyzed the data. YY and FKS finalized the manuscript. Both authors read and approved the final manuscript.

\section{Acknowledgements \\ We would like to thank Hajime Tsukada and the Lake Yogo Fishery Cooperative Association for providing information on the bluegill in Lake Yogo. We would also like to thank the River Yogo Management Office for supplying data on the inflowing water from Lake Biwa. Additional linguistic support was provided by Ted Knoy. Fish samples were collected with the consent of the Lake Yogo Fishery Cooperative Association. Experiments in this study complied with the current laws of Japan.}

Received: 18 March 2013 Accepted: 7 June 2013

Published: 30 September 2013

\section{References}

Aday DD, Wahl DH, Philipp DP (2003) Assessing population-specific and environmental influences on bluegill life histories: a common garden approach. Ecology 84:3370-3375

Banner A, Hyatt M (1975) Induced spawning of bluegill sunfish. Progr Fish-Cult $37: 173-180$

Bayne DR, Reutebuch E, Seesock WC (2002) Relative motility of fishes in a southeastern reservoir based on tissue polychlorinated biphenyl residues. $N$ Am J Fish Manage 22:122-131

Cargnelli LM, Neff BD (2006) Condition-dependent nesting in bluegill sunfish Lepomis macrochirus. J Anim Ecol 75:627-633
Fish PA, Savitz J (1983) Variations in home ranges of largemouth bass, yellow perch, bluegills, and pumpkinseeds in an Illinois lake. Trans Am Fish Soc 112:147-153

Fox MG, Crivelli AJ (1998) Body size and reproductive allocation in a multiple spawning centrarchid. Can J Fish Aquat Sci 55:737-748

Gross MR (1982) Sneakers, satellites and parentals: polymorphic mating strategies in North American sunfishes. Z Tierpsychol 60:1-26

Gross MR, MacMillan AM (1981) Predation and the evolution of colonial nesting in bluegill sunfish (Lepomis macrochirus). Behav Ecol Sociobiol 8:163-174

Horie S, Kanari S, Nakao K (1975) Buried forest in Lake Yogo-ko and its significance for the study of past bio-environments. Proc Jpn Acad 51:669-674

Iguchi K, Yamaguchi M (1994) Adaptive significance of inter- and intrapopulational egg size variation in ayu Plecoglossus altivelis (Osmeridae). Copeia 1994:184-190

Jennings MJ, Claussen JE, Philipp DP (1997) Effect of population size structure on reproductive investment of male bluegill. N Am J Fish Manage 17:516-524

Knapp RA, Vredenburg VT (1996) Spawning by California golden trout: characteristics of spawning fish, seasonal and daily timing, redd characteristics, and microhabitat preferences. Trans Am Fish Soc 125:519-531

Lemke AE (1977) Optimum temperature for growth of juvenile bluegills. Progr Fish-Cult 39:55-57

Mann RHK (1980) The growth and reproductive strategy of the gudgeon, Gobio gobio (L.), in two hard-water rivers in southern England. J Fish Biol 17:163-176

Miranda LE, Muncy RJ (1987) Recruitment of young-of-year largemouth bass in relation to size structure of parental stock. N Am J Fish Manage 7:131-137

Mittelbach GG (1981) Foraging efficiency and body size: a study of optimal diet and habitat use by bluegills. Ecology 62:1370-1386

Nakai K (2002) Bluegill. In: Handbook of alien species in Japan (ed) The ecological society of Japan. Chijinshokan, Tokyo, p 119, (in Japanese)

Nakamura N, Kasahara S, Yada T (1969) Studies on the usefulness of the bluegill sunfish, Lepomis macrochirus Rafinesque, as an experimental standard animal. I. On the breeding habits. J Faculty Fish Anim Husb Hiroshima Univ 8:1-11, (in Japanese with English summary)

Nakao H, Fujita K, Kawabata T, Nakai K, Sawada H (2006) Breeding ecology of bluegill Lepomis macrochirus, an invasive alien species, in the north basin of Lake Biwa, central Japan. Jpn J Ichthyol 53:55-62 (in Japanese with English summary)

Paukert CP, Willis DW, Bouchard MA (2004) Movement, home range, and site fidelity of bluegills in a Great Plains lake. N Am J Fish Manage 24:154-161

Slotte A, Johannessen A, Kjesbu OS (2000) Effects of fish size on spawning time in Norwegian spring-spawning herring. J Fish Biol 56:295-310

Tsujimura S (2004) Water management of Lake Yogo targeting internal phosphorus loading. Lakes Reserv Res Manage 9:171-179

Tsukada H, Tsujimura S, Nakahara H (2006) Seasonal succession of phytoplankton in Lake Yogo over 2 years: effect of artificial manipulation. Limnology 7:3-14

Vandeperre F, Methven DA (2007) Do bigger fish arrive and spawn at the spawning grounds before smaller fish: Cod (Gadus morhua) predation on beach spawning capelin (Mallotus villosus) from coastal Newfoundland. Estuar Coast Shelf Sci 71:391-400

Werner EE, Hall DJ (1988) Ontogenetic habitat shifts in bluegill: the foraging ratepredation risk trade-off. Ecology 69:1352-1366

West G (1990) Methods of assessing ovarian development in fishes: a review. Aust J Mar Freshw Res 41:199-222

Yamamoto Y, Kao SJ (2012) Relationship between latitude and growth of bluegill Lepomis macrochirus in Lake Biwa, Japan. Ann Zool Fen 49:36-44

Yamamoto Y, Shiah FK (2012) Spatial variation in the spawning season of bluegill Lepomis macrochirus in Lake Biwa, Japan. Zool Stud 51:1446-1453

Yamamoto Y, Shiah FK (2013) Potential importance of lagoons as breeding grounds for bluegill Lepomis macrochirus in Lake Biwa, Japan. Limnology 14:31-37

Yamamoto Y, Tsukada H, Nakai D (2010) Latitudinal gradient in the body weight of bluegill Lepomis macrochirus in Lake Biwa, Japan. Zool Stud 49:625-631

Yamamoto Y, Tsukada H, Shiah FK (2011) Latitudinal gradient in the ovary weight of bluegill Lepomis macrochirus in Lake Biwa, Japan. Ethol Ecol Evol 23:291-299

Yonekura R, Kawamura K, Uchii K (2007) A peculiar relationship between genetic diversity and adaptability in invasive exotic species: bluegill sunfish as a model species. Ecol Res 22:911-919

\section{doi:10.1186/1810-522X-52-19}

Cite this article as: Yamamoto and Shiah: Spatial variation in reproductive measures of female bluegill Lepomis macrochirus Rafinesque in a small lake with diverse thermal conditions. Zoological Studies 2013 52:19. 